Review

\title{
New Prospect for Cancer Cachexia: Medical Cannabinoid
}

\author{
Jing Wang*, Yanling Wang\#, Mengting Tong, Hongming Pan, Da Li ${ }^{\bowtie}$ \\ Department of Medical Oncology, Sir Run Run Shaw Hospital, Zhejiang University School of Medicine, Hangzhou, Zhejiang, China \\ *First author \\ \# Co-first author \\ $\bowtie$ Corresponding author: Dr. Li Da. Email: lidaonconew@zju.edu.cn \\ (c) Ivyspring International Publisher. This is an open access article distributed under the terms of the Creative Commons Attribution (CC BY-NC) license \\ (https://creativecommons.org/licenses/by-nc/4.0/). See http://ivyspring.com/terms for full terms and conditions.
}

Received: 2018.07.02; Accepted: 2018.10.28; Published: 2019.01.01

\begin{abstract}
Cachexia is a common term for the wasting symptoms which may appear in almost every chronic illness, such as AIDS, tuberculosis, and cancer. Cancer cachexia (CCA) is a result of the interaction between the host and the tumor, mainly manifested in short-term wasting, malnutrition, and so on. Due to the chronic food shortages, absorption dysfunction and metabolic disorders, all of these eventually lead to hypoimmunity, organ failure, and higher susceptibility to pathogenic microorganisms. And then increased morbidity and mortality rates as well as reduced tolerance to anti-cancer treatments will be resulted in patients with CCA. Up to now, no standard guidelines have been established for cachexia treatment. Moreover, progestagens, the only drugs approved by FDA for cancer-related cachexia, can only increase adipose tissue and have not been confirmed to augment lean body mass. Cannabinoid, such as $\Delta$-9-tetrahydrocannabinol (THC) and cannabidiol, is one of a class of diverse chemical compounds. Previous studies have showed that cannabinoid had considerable potential to improve the appetite, body weight, body fat level, caloric intake, mood, quality of life in kinds of diseases. This review will elaborate the anti-CCA role of cannabinoid and explore that whether cannabinoid is effective for CCA and provide a basis for guiding clinical drug use.
\end{abstract}

Key words: cancer; cachexia; cannabinoid; review; clinical trials

\section{Introduction}

CCA has attacked approximately $50 \%-80 \%$ of the cancer patients ${ }^{[1]}$ and been implicated in $25 \%$ of cancer deaths [2]. In addition, as a multifactorial syndrome, CCA is frequently unrecognized and undertreated, and cannot be fully reversed only by nutritional support ${ }^{[3]}$. Abnormalities in protein and amino acid metabolism and the appearance of energy balance disorder (energy intake is decreased and/or energy expenditure is increased) form the essence of CCA. All these unfavorable changes may further lead to a variety of metabolic disorders. Subsequently, malnutrition may affect the effectiveness of drug therapy; it can increase chemotherapy toxicity, decreasing the positive influence on tumor treatment, and even leads to elevated treatment-related mortality. Nevertheless, the increase in food intake does not prevent this negative outcome, and presently, there is no effective therapy for cachexia. At present, however, the main treatment for CCA is Radiotherapy, chemotherapy, surgical resection and other treatment programs, which can in turn aggravate the weakness of cancer patients. for primary tumors.

Successful tumor treatment requires the implementation of a comprehensive multidisciplinary approach. Hence, anti-CCA treatment must address the following important therapeutic aspects: (1) correction of the cachexia status; (2) control of the symptoms; (3) amelioration of bodily functions; and (4) improvement of the quality of life. Generally speaking, anti-CCA treatment not only can improve the quality of life (QOL), but also promote the effectiveness of cancer treatment.

Therefore, the treatment of CCA has entered a vicious circle, and urgent need to develop effective new drugs. 


\section{The medical application of Cannabinoid}

There are at least 113 cannabinoids and 120 synthetic cannabinoids identified in cannabis ${ }^{[4]}$. Cannabinoid acts on the corresponding receptors in cells, then alter neurotransmitter release in the brain, and eventually led to varying pharmacologic responses based on formulation and patient characteristics.

In recent years, researchers have gradually found that cannabinoid, in addition to recreational use, also have possible applications as the supportive therapy or palliative medicine. In German pharmaceutical legislation, from the very beginning cannabinoid (nabiximol) is only approved for multiple sclerosis, but now it is widely used for neuropathic pain, cancer-associated pain and AIDS-related cachexia. Dronabinol, a synthetic form of THC and the most notable cannabinoid, has been approved by the FDA to increase appetite for AIDS and antiemetic for chemotherapy $\left.{ }^{[5,} 6\right]$. Moreover, previous studies also showed that cannabinoid can alleviated pain, nausea, and vomiting in patients with multiple sclerosis [7], HIV [8], anorexia nervosa [9], obesity [10], and type 2 diabetes [11], and a variety of neurological disorders, such as epilepsy ${ }^{[12]}$, Tourette's syndrome[13], Alzheimer's disease ${ }^{[14],}$ and Huntington's disease ${ }^{[15]}$. Furthermore, this bioactive substance attracted intensive research interest for application in cardiac cachexia treatment ${ }^{[16]}$.

\section{Cannabinoid Receptors and Cannabinoids}

Nevertheless, whether its effects will be identical in CCA requires further confirmation. The mechanism of cannabinoid activity is mainly related to G-protein coupled cannabinoid 1 and 2 receptors (CB1/2). CB1 are mostly found in the brain, such as cortex, hippocampus, basal ganglia and cerebellum, and then have corresponding effects on memory, cognition, depression, anxiety, feeding, movement and nociception ${ }^{[17,18]}$. The psychotropic side effect of cannabinoid, such as euphoria, excitement, and altered sensory perception, is the main reason why it has not been recognized as a legitimate drug for so many years. Therefore, on the one hand, the use of $\mathrm{CB} 1$ play some spiritual role in further regulating the central nervous system (CNS), on the other hand, selective block CB1 may significantly reduce the mental side effects of drugs from cannabinoid. CB2 was previously thought to be expressed only in the immune system, however, recent studies found that CB2 receptors also can be expressed in CNS[19], such as ventral posterior nucleus of the thalamus and spinal nerve ligation ${ }^{[20]}$, which may also be a promise to regulate CNS function. Rowley $\mathrm{S}^{[21]}$ et al. did an interesting experiment and found that CB1-knockout mices showed more seizures susceptibility than CB2-knockout mices, but none of them exhibit seizures, but $30 \%$ of the double-knockout mice showed behavioral epilepsy.

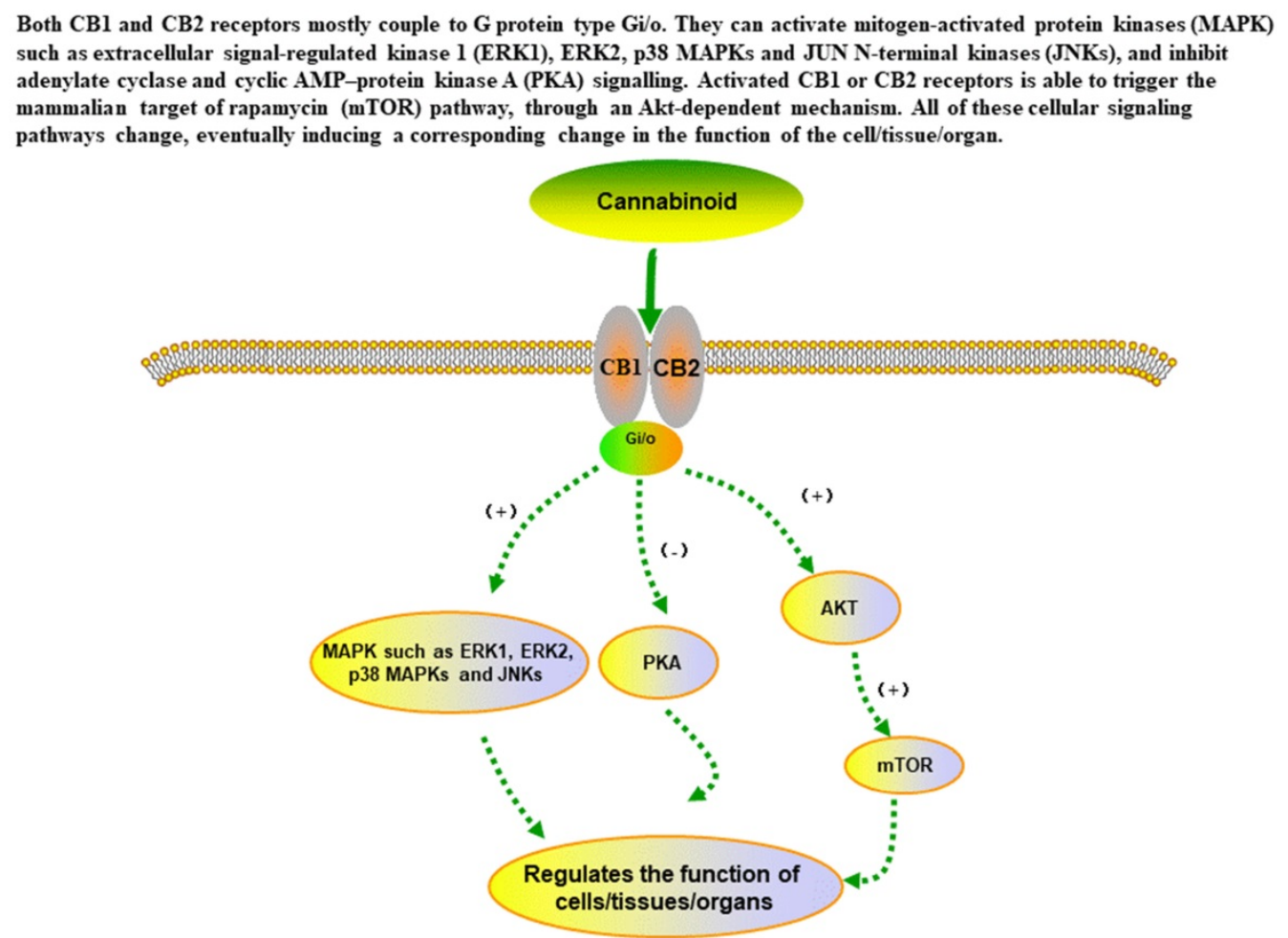

Figure 1. The main signaling pathways of cannabinoid in the in cells. 


\section{Pharmacodynamics mechanism of cannabinoids}

The analgesic mechanism of cannabis ${ }^{[22]}$ may derived from the regulation the activity of rostral ventromedial medulla oblongata neurons, relieve pain pathway and regulate the anti-inflammatory effects through prostaglandin synthesis inhibition. Moreover, Borgelt LM summed up the multiple clinical studies containing different THC doses and found that THC did have analgesic effects on patients with multiple diseases.

Dronabinol and nabilone have already been approved by the FDA for the using of chemotherapy-induced nausea and vomiting (CINV), anorexia associated with weight loss in patients with the acquired immunodeficiency syndrome.

Above on, it can exert a moderating effect on obesity, metabolism, and pain by activating pathways that are cannabinoid receptors scattered all over the body ${ }^{[23]}$. In addition, marijuana was also found to exert novel anticancer properties through induction of cancer cell death. A considerable number of studies ${ }^{24,}$ 25] showed that THC and other cannabinoids can induce apoptosis of glioma cells, slowing the growth of different types of tumors. cannabinoid was approved by the FDA for use as an appetite stimulant and was also shown to cause emotional excitement ${ }^{[26] .}$ As early as 1974, Davies[27] found that THC improved night sleep, reduced pain, increased fatigue and confusion, and decreased elation and vigor. Then scientists[27-29] discover that cannabinoid use is associated with weight gain, increased appetite, decreased nausea, improvement in mood, relief of pain, and so on. This review will explore that whether cannabinoid is effective for CCA and provide a basis for guiding clinical drug use.

\section{RCTs related to the anti-CCA effects of cannabinoid}

There have been a lot of experiments in vivo or in vitro on cannabinoid and CCA, however, in which few randomized controlled trials (RCTs) of high quality reported.

Brisbois et al. showed the results of a pilot study (NCT00316563) in 2011, and cannabinoid (THC) is being used as an appetite stimulant for treatment of cancer-induced anorexia. The results showed that compared with placebo, THC-treated patients reported premeal appetite $(\mathrm{P}=0.05)$, quality of sleep $(P=0.025)$ and relaxation $(P=0.045)$ increased, and food 'tasted better' $(\mathrm{P}=0.04)$ simultaneously. QOL scores was improved in the THC group but was not different from placebo. Furthermore, the changes in lean body weight of participants were not recorded in this experiment. Therefore, THC may be useful in CCA, but still require verification in larger trials.

Johnson et al. reported the findings of intractable cancer-related pain compared in THC:CBD extract and THC extract. There was statistically significant for a reduction in pain with the THC:CBD extract $(0.67$ points, $\mathrm{P}=0.014)$ rather than the THC extract $(0.32$ points, $\mathrm{P}=0.245$ ) compared to placebo. As for NRS sleep quality or nausea scores, no significant group differences were reached. The participants ' weight changes were also not reflected in the text. Rapid concluded, THC:CBD extract may be a useful adjunctive treatment for relief of pain in patients with advanced cancer, which encourage us to explore its value in analgesic, QOL and CCA. Perhaps the differences between the experimental and placebo groups could be better reflected in longer test cycles or other conditions.

Table 1. Research summaries comparing the effects of cannabinoids and placebo in CCA.

\begin{tabular}{|c|c|c|c|c|c|c|}
\hline $\begin{array}{l}\text { Study ID or RCT } \\
\text { number }\end{array}$ & Study method & Human subjects & Interventional group & $\begin{array}{l}\text { Control } \\
\text { group }\end{array}$ & $\begin{array}{l}\text { Follow } \\
\text { up (d) }\end{array}$ & Outcomes \\
\hline Brisbois 2011[30] & $\begin{array}{l}\text { parallel-group } \\
\text { RCTs }\end{array}$ & $\begin{array}{l}\text { advanced cancer } \\
\text { patients }\end{array}$ & THC $(2.5 \mathrm{mg}, \mathrm{n}=24)$ & $\begin{array}{l}\text { Placebo }(\mathrm{n} \\
=22)\end{array}$ & 19 & Appetite, AEs, QOL \\
\hline Johnson $2010^{[28]}$ & $\begin{array}{l}\text { parallel-group } \\
\text { RCTs }\end{array}$ & $\begin{array}{l}\text { advanced cancer } \\
\text { patients }\end{array}$ & $\begin{array}{l}\text { THC:CBD extract }(2.7 \mathrm{mg} \text { THC and } 2.5 \mathrm{mg} \\
\text { CBD, } \mathrm{n}=60), \text { THC extract }(2.7 \mathrm{mg} \text { THC, } \mathrm{n}=58)\end{array}$ & $\begin{array}{l}\text { Placebo }(\mathrm{n} \\
=59)\end{array}$ & 14 & Appetite, AEs, QOL \\
\hline Strasser $2006^{[31]}$ & $\begin{array}{l}\text { parallel-group } \\
\text { RCTs }\end{array}$ & $\begin{array}{l}\text { advanced cancer } \\
\text { patients }\end{array}$ & $\begin{array}{l}\text { CE (standardized for } 2.5 \mathrm{mg} \text { THC and } 1 \mathrm{mg} \\
\text { cannabidiol, } \mathrm{n}=95) \text { or THC }(2.5 \mathrm{mg}, \mathrm{n}=100)\end{array}$ & $\begin{array}{l}\text { Placebo }(\mathrm{n} \\
=48)\end{array}$ & 42 & Body weight, appetite, AEs, QOL \\
\hline NCT03245658 & $\begin{array}{l}\text { Crossover } \\
\text { Assignment }\end{array}$ & $\begin{array}{l}\text { pancreatic cancer } \\
\text { patients }\end{array}$ & THC $25 \mathrm{mg} / \mathrm{ml}$ and CBD 50mg/ml $(\mathrm{n}=32)$ & $\mathrm{N} / \mathrm{A}$ & 4 weeks & $\begin{array}{l}\text { Energy and protein intake, lean body } \\
\text { mass, appetite, mortality, QOL }\end{array}$ \\
\hline NCT02802540 & $\begin{array}{l}\text { parallel-group } \\
\text { RCTs }\end{array}$ & $\begin{array}{l}\text { Non-small cell lung } \\
\text { cancer (NSCLC) } \\
\text { patients }\end{array}$ & $1 \mathrm{mg}$ nabilone & placebo & 8 weeks & $\begin{array}{l}\text { Anorexia, percentage weight loss, body } \\
\text { mass index, subjective global } \\
\text { assessment, QOL, AEs }\end{array}$ \\
\hline Jatoi $2002^{[32]}$ & $\begin{array}{l}\text { Crossover } \\
\text { Assignment }\end{array}$ & $\begin{array}{l}\text { advanced cancer } \\
\text { patients }\end{array}$ & $\begin{array}{l}\text { (1) megestrol acetate } 800 \mathrm{mg} / \mathrm{d} \text { plus placebo, (2) } \\
\text { dronabinol } 2.5 \mathrm{mg} \text { twice a day plus placebo, or } \\
\text { (3) both agents }\end{array}$ & N/A & 4 weeks & weight, appetite, AEs, QOL \\
\hline Cote 2016 [33] & $\begin{array}{l}\text { parallel-group } \\
\text { RCTs }\end{array}$ & $\begin{array}{l}\text { squamous cell } \\
\text { carcinoma patients }\end{array}$ & $0.5 \mathrm{mg}$ nabilone & placebo & 4 weeks & QOL, pain, nausea, appetite, AEs \\
\hline
\end{tabular}


Moreover, it was a study in 2006, and Strasser et al. compared the effects of cannabis extract (CE), THC, and placebo on appetite and QOL in patients with CCA. At last, the differences of mean improvement in appetite patients taking CE and PL were not obvious (mean, $5.4 \mathrm{~mm}$; SD, $24.7 \mathrm{~mm}$; and mean, $5.8 \mathrm{~mm}$; SD, $23.8 \mathrm{~mm}$, respectively). As for THC group, the mean improvement was even $0.6 \mathrm{~mm}$ (SD, $18.5 \mathrm{~mm}$ ). Besides, no differences of QOL, weight, cannabinoid-related toxicity, mood and nausea can be found between the three groups. Can we simply draw the conclusion and deny the effect of cannabinoid on CCA? More RCTs have the right to speak.

There is also a clinical trial in which patients are being recruited and another has not yet been recruited, and we are looking forward to their findings.

\section{Direct antitumor effect of cannabinoid}

Except for the palliative effects of cannabinoid in cancer patients, it also exhibits antitumor effects on a wide range of animal models of cancer. Previous studies have shown that THC, synthesized receptor agonists of $\mathrm{CB} 1$ and $\mathrm{CB} 2$, as well as endocannabinoids, all have the potential to trigger apoptosis ${ }^{[34]}$, monitor tumor cell growth ${ }^{[35]}$, combat tumor cell invasion and metastasis ${ }^{[36]}$, as well as resist angiogenesis ${ }^{[37]}$. To sum up, they may have been involved in a series of complex biological processes that eventually contribute to the progression of a variety of cancers[37, 38] (glioma, melanoma, and pancreatic carcinoma, hepatocellular carcinoma, head and neck squamous cell carcinoma and so on), and may provide a therapeutic target to inhibit the tumors progression.

As we know, the fundamental need to correct CCA is to control the cancer itself, so if cannabinoid has the function of fighting cancer and increasing appetite, it will undoubtedly be a bright dawn in the field of cancer nutrition therapy.

\section{Safety issue of cannabinoid}

The safety issue is still the bottom line in ascertaining the efficacy and practicality of a drug. Treatment-related AEs of cannabinoid includes nausea, fatigue, pain, anemia, dizziness, dyspnea, diarrhea, obstipation, somnolence, raised $\gamma_{-} \mathrm{GT}$, hypercalcemia, hypotension and so on. Besides, a multi-institutional study in AIDs patients found that dronabinol use was safe and well tolerated ${ }^{[39]}$. Though we cannot simply speculate that there was a higher risk of AEs in the cannabinoids group, more research data are needed to demonstrate the safety of marijuana.

\section{CCA and its outlook}

CCA can occur not only at the end stage of malignancy but at any phase of its development. Weight loss should be considered a red alert for cachexia patients. Pancreatic and gastric cancer patients are high-risk groups for severe weight loss. However, patients with non-Hodgkin's lymphoma, breast cancer, acute non-lymphocytic leukemia, and sarcoma are less likely to lose weight. A weight loss of $10 \%$ can be considered as a serious problem that may cause a decrease in respiratory function. Fortunately, cachexia can be prevented and treated, and an interruption or delay of the process can substantially improve the clinical outcome of the patient. Hence, cachexia treatment consists of three critical steps: appropriate antitumor treatment, nutrition intervention, and supportive pharmacologic therapy.

Although our research on the biological characteristics and molecular mechanisms of CCA has made some achievements in the past decades, there are still many unknowns that need to be determined. For example, evaluation is required of the prognostic value of blood and urine biomarkers of cachexia patients, such as markers of muscle degradation, genetic predispositions, and those in the plasma or the adipose tissue. Furthermore, research community needs to understand if early-stage detection of cachexia tendency in cancer patients is possible, which would enable the undertaking of timely remedial measures.

\section{Acknowledgments}

This work was supported by the National Natural Science Foundation of China, 81573003. We sincerely appreciate all the participants in this paper. We would also like to thank all the scholars whose article was cited in this paper, without their inspiration and help from the research results of these scholars, I will not be able to complete the final writing of this paper. Then we also appreciate the work of the editors and anonymous reviewers.

\section{Competing Interests}

The authors have declared that no competing interest exists.

\section{References}

[1] Argiles J M, Busquets S, Stemmler B, et al. Cancer cachexia: understanding the molecular basis[J]. Nat Rev Cancer, 2014,14(11):754-762.

[2] Bray N. Muscle disorders: Combating cachexia in cancer[J]. Nat Rev Drug Discov, 2015,14(11):748.

[3] Barton M K. Cancer cachexia awareness, diagnosis, and treatment are lacking among oncology providers[J]. CA Cancer J Clin, 2017,67(2):91-92.

[4] Aizpurua-Olaizola O, Soydaner U, Ozturk E, et al. Evolution of the Cannabinoid and Terpene Content during the Growth of Cannabis sativa Plants from Different Chemotypes[J]. J Nat Prod, 2016,79(2):324-331. 
[5] Badowski M E, Yanful P K. Dronabinol oral solution in the management of anorexia and weight loss in AIDS and cancer[J]. Ther Clin Risk Manag, 2018,14:643-651.

[6] Zutt M, Hanssle H, Emmert S, et al. [Dronabinol for supportive therapy in patients with malignant melanoma and liver metastases][J]. Hautarzt, 2006,57(5):423-427.

[7] Langford R M, Mares J, Novotna A, et al. A double-blind, randomized, placebo-controlled, parallel-group study of THC/CBD oromucosal spray in combination with the existing treatment regimen, in the relief of central neuropathic pain in patients with multiple sclerosis[J]. Journal of Neurology, 2013,260(4):984-997.

[8] Bedi G, Foltin R W, Gunderson E W, et al. Efficacy and tolerability of high-dose dronabinol maintenance in HIV-positive marijuana smokers: A controlled laboratory study[J]. Psychopharmacology, 2010,212(4):675-686.

[9] Andries A, Frystyk J, Flyvbjerg A, et al. Changes in IGF-I, urinary free cortisol and adipokines during dronabinol therapy in anorexia nervosa: Results from a randomised, controlled trial[J]. Growth Hormone and IGF Research, 2015,25(5):247-252

[10] Sipe J C, Scott T M, Murray S, et al. Biomarkers of endocannabinoid system activation in severe obesity[J]. PLoS ONE, 2010,5(1).

[11] Jadoon K A, Ratcliffe S H, Barrett D A, et al. Efficacy and safety of cannabidiol and tetrahydrocannabivarin on glycemic and lipid parameters in patients with type 2 diabetes: A randomized, double-blind, placebo-controlled, parallel group pilot study[J]. Diabetes Care, 2016,39(10):1777-1786.

[12] Porter B E, Jacobson C. Report of a parent survey of cannabidiol-enriched cannabis use in pediatric treatment-resistant epilepsy[J]. Epilepsy Behav, 2013,29(3):574-577.

[13] Muller-Vahl K R, Schneider U, Prevedel H, et al. Delta 9-tetrahydrocannabinol (THC) is effective in the treatment of tics in Tourette syndrome: a 6-week randomized trial[J]. J Clin Psychiatry, 2003,64(4):459-465.

[14] Campbell V A, Gowran A. Alzheimer's disease; taking the edge off with cannabinoids?[J]. Br J Pharmacol, 2007,152(5):655-662.

[15] Sagredo O, Pazos M R, Valdeolivas S, et al. Cannabinoids: novel medicines for the treatment of Huntington's disease[J]. Recent Pat CNS Drug Discov, 2012,7(1):41-48

[16] von Haehling S, Lainscak M, Springer J, et al. Cardiac cachexia: a systematic overview[J]. Pharmacol Ther, 2009,121(3):227-252.

[17] Fraguas-Sanchez A I, Martin-Sabroso C, Torres-Suarez A I. INSIGHT ON THE IMPACT OF ENDOCANNABINOID SYSTEM IN CANCER: A REVIEW[J]. Br J Pharmacol, 2018.

[18] Valverde O, Karsak M, Zimmer A. Analysis of the endocannabinoid system by using CB1 cannabinoid receptor knockout mice[J]. Handb Exp Pharmacol, 2005(168):117-145.

[19] Stempel A V, Stumpf A, Zhang H Y, et al. Cannabinoid Type 2 Receptors Mediate a Cell Type-Specific Plasticity in the Hippocampus[J]. Neuron, 2016,90(4):795-809.

[20] Zutt M, Hanssle H, Emmert S, et al. [Dronabinol for supportive therapy in patients with malignant melanoma and liver metastases][J]. Hautarzt, 2006,57(5):423-427.

[21] Rowley S, Sun X, Lima I V, et al. Cannabinoid receptor $1 / 2$ double-knockout mice develop epilepsy[J]. Epilepsia, 2017,58(12):e162-e166.

[22] Borgelt L M, Franson K L, Nussbaum A M, et al. The pharmacologic and clinical effects of medical cannabis[J]. Pharmacotherapy, 2013,33(2):195-209.

[23] Kaminska B, Ellert-Miklaszewska A. Cannabinoid signalling in glioma cells[J]. Springerplus, 2015,4(Suppl 1):L11.

[24] Beal J, Flynn N. AIDS-associated anorexia[J]. J Physicians Assoc AIDS Care, 1995,2(1):19-22.

[25] Davies B H, Weatherstone R M, Graham J D, et al. A pilot study of orally administered Delta(1)-trans-tetrahydrocannabinol in the management of patients undergoing radiotherapy for carcinoma of the bronchus[J]. Br J Clin Pharmacol, 1974,1(4):301-306.

[26] James J S. Marijuana safety study completed: weight gain, no safety problems[J]. AIDS Treat News, 2000(348):3-4.

[27] Beal J E, Olson R, Laubenstein L, et al. Dronabinol as a treatment for anorexia associated with weight loss in patients with AIDS.[J]. Journal of Pain \& Symptom Management, 1995,10(2):89-97.

[28] Johnson J R, Burnell-Nugent M, Lossignol D, et al. Multicenter, double-blind, randomized, placebo-controlled, parallel-group study of the efficacy, safety, and tolerability of THC:CBD extract and THC extract in patients with intractable cancer-related pain[J]. J Pain Symptom Manage, 2010,39(2):167-179.

[29] Foltin R W, Fischman M W, Byrne M F. Effects of smoked marijuana on food intake and body weight of humans living in a residential laboratory[J]. Appetite, 1988,11(1):1-14

[30] Brisbois T D, de Kock I H, Watanabe S M, et al. Delta-9-tetrahydrocannabinol may palliate altered chemosensory perception in cancer patients: results of a randomized, double-blind, placebo-controlled pilot trial[J]. Ann Oncol, 2011,22(9):2086-2093.

[31] Strasser F, Luftner D, Possinger K, et al. Comparison of orally administered cannabis extract and delta-9- tetrahydrocannabinol in treating patients with cancer-related anorexia-cachexia syndrome: A multicenter, phase III, randomized, double-blind, placebo-controlled clinical trial from the Cannabis-In-Cachexia-Study-Group[J]. Journal of Clinical Oncology, 2006,24(21):3394-3400.
[32] Jatoi A, Windschitl H E, Loprinzi C L, et al. Dronabinol versus megestrol acetate versus combination therapy for cancer-associated anorexia: a North Central Cancer Treatment Group study[J]. J Clin Oncol, 2002,20(2):567-573.

[33] Cote M, Trudel M, Wang C, et al. Improving Quality of Life With Nabilone During Radiotherapy Treatments for Head and Neck Cancers: A Randomized Double-Blind Placebo-Controlled Trial[J]. Ann Otol Rhinol Laryngol, 2016,125(4):317-324.

[34] Massi P, Valenti M, Vaccani A, et al. 5-Lipoxygenase and anandamide hydrolase (FAAH) mediate the antitumor activity of cannabidiol, a non-psychoactive cannabinoid[J]. Journal of Neurochemistry, 2008,104(4):1091-1100.

[35] Alexander S P, Mathie A, Peters J A. Guide to Receptors and Channels (GRAC), 5th edition[J]. Br J Pharmacol, 2011,164 Suppl 1:S1-S324.

[36] Ramer R, Merkord J, Rohde H, et al. Cannabidiol inhibits cancer cell invasion via upregulation of tissue inhibitor of matrix metalloproteinases-1[J]. Biochem Pharmacol, 2010,79(7):955-966.

[37] Ramer R, Fischer S, Haustein $M$, et al. Cannabinoids inhibit angiogenic capacities of endothelial cells via release of tissue inhibitor of matrix metalloproteinases-1 from lung cancer cells[J]. Biochemical Pharmacology, 2014,91(2):202-216

[38] Suk K T, Mederacke I, Gwak G Y, et al. Opposite roles of cannabinoid receptors 1 and 2 in hepatocarcinogenesis[J]. Gut, 2016,65(10):1721-1732.

[39] Beal J E, Olson R, Laubenstein L, et al. Dronabinol as a treatment for anorexia associated with weight loss in patients with AIDS[J]. Journal of Pain and Symptom Management, 1995,10(2):89-97. 